\title{
MicroRNA-146a and its adapter proteins are affected by diabetes in rat's heart
}

\author{
Eftekhar $\mathrm{E}^{1}$, Doustaki Zaboli $\mathrm{M}^{2}$, Katebi $\mathrm{M}^{3}$, Ghadiri Soufi $\mathrm{F}^{3}$ \\ Department of Biochemistry, Faculty of Medicine, Hormozgan University of Medical Sciences, \\ Bandar Abbas, Iran.soufifg@tbzmed.ac.ir
}

\begin{abstract}
OBJECTIVES: This study was conducted to explore whether microRNA-146a and its adapter proteins (TNF- $\alpha$ receptor-associated factor 6 (TRAF6) and interleukin-1 receptor-associated kinase 1 (IRAK1)) are affected by diabetes in the rat heart.

METHODS: Twelve male Sprague-Dawley rats were randomized into control and diabetic groups $(n=6)$. Streptozotocin-nicotinamide experimental model was used to induce type 2 diabetes. The gene expression of MicroRNA-146a, nuclear factor-KB (NF-KB), IRAK1 and TRAF6, as well as NF-KB activity, IRAK1 and TRAF6 protein levels were measured. Moreover, NF-KB activity was measured in response to miR-146a mimic transfection $(20 \mathrm{nmol})$ in human umbilical vein endothelial cells (HUVECs) under hyperglycemic condition (25 mM D-glucose for $24 \mathrm{~h}$ ).

RESULTS: The expression of MicroRNA-146a was increased in the heart tissue, 2 months after diabetes induction and in HUVECs. Also, the mRNA and protein levels of NF-KB, IRAK1 and TRAF6 were increased in the heart of diabetic rats. Moreover, transfection of miR-146a mimic prevented from a significant increase of NF-KB activity in hyperglycemic HUVECs.

CONCLUSION: Presumably, a defect in the regulation of IRAK1 and TRAF6 can weaken miR-146a regulatory effect and provides a situation for sustained activation of NF-KB and its targets to promote cardiac cells toward abnormalities (Fig. 3, Ref. 28). Text in PDF www.elis.sk.
\end{abstract}

KEY WORDS: diabetes, heart, microRNA-146a, NF-KB, IRAK1, TRAF6.

\section{Introduction}

Diabetes mellitus is a serious global health problem resulting from insulin insufficiency or inefficiency which, its prevalence is increasing dramatically, and due to the rising rate of obesity and sedentary lifestyle, about 552 million people are estimated to be suffering from diabetes mellitus worldwide by $2030(1,2)$. Diabetes-induced hyperglycemia and the corresponding glucotoxicity result in macro and microvascular complications such as diabetic neuropathy, nephropathy, retinopathy, and cardiomyopathy (3).

${ }^{1}$ Department of Biochemistry, Faculty of Medicine, Hormozgan University of Medical Sciences, Bandar Abbas, Iran, ${ }^{2}$ Department of Physiology, Faculty of Medicine, Hormozgan University of Medical Sciences, Bandar Abbas, Iran, and ${ }^{3}$ Stem cells Research Center, Hormozgan University of Medical Sciences, Bandar Abbas, Iran

Address for correspondence: Dr. F.G. Soufi, PhD, Stem cells Research Center, Shahid Mohammadi hospital, Jomhouri Boulevard, Bandar Abbas, Postal Code: 7915736973, Iran.

Phone/Fax: +98.763.3338965

Grant support: The grant of this study was fully supported by Stem cells Research Center, Hormozgan University of Medical Sciences, Bandar Abbas, Iran.

Acknowledgements: The grant of this study was supported by Stem cells Research Center, Hormozgan University of Medical Sciences, Bandar Abbas, Iran. Our data in this work were derived from the thesis of Ms. Maryam Doustaki Zaboli for a Master of Science degree in physiology (thesis serial number: 90-ph-3).
Patients with diabetes have a significantly increased risk of premature mortality and an increased risk of microvascular and cardiovascular complications. (4). Despite numerous investigations have been directed toward increasing our knowledge about the mechanisms involved in the pathogenesis of diabetes-related angiopathies, the precise mechanism is still unclear, and needs to be clarified by further studies.

In recent years several studies have demonstrated significant alterations in the expression level of microRNA-146a (miR-146a) in the blood and peripheral tissues of both diabetic patients and animals (5-15). MiR-146a like other members of microRNAs family is a small, noncoding, and single strand RNA that modulates target gene expression at post-transcriptional level by binding to target messenger RNA (mRNA), and regulating its stability and translation (16).

It has been suggested that miR-146a participates in many physiological and pathological processes, in part by regulating the activation of a master pro-inflammatory transcription factor, nuclear factor kappa $\mathrm{B}(\mathrm{NF}-\kappa \mathrm{B})(16)$. It is believed that activation of NF- $\kappa \mathrm{B}$ promotes the transcription of the miR-146a gene that, in turn down-regulates two key adapter molecules, TNF receptor associated factor 6 (TRAF6) and Interleukin-1 receptor-associated kinase 1 (IRAK1), to decrease NF- $\kappa$ B activity (17). However, this negative feedback loop has not been demonstrated by several investigations $(12,13,18,19)$.

While a decreased expression of miR-146a has been reported in diabetic mouse wounds (5), diabetic rats aorta, sciatic nerve, 
kidney, heart and dorsal root ganglia (6-9), glycated albumin- and high glucose-stimulated endothelial cells (10), and in serum and peripheral blood mononuclear cells of type 1 and 2 diabetic patients $(11,12)$, an increased miR-146a expression has also been documented in diabetic kidney (13), and in plasma and limbal corneal epithelium compartment of diabetic patients $(14,15)$.

While growing evidence indicates that miR-146a plays a role in the pathogenesis of diabetes related complications, there is little information available concerning the expression level of this microRNA and its role in the regulation of NF- $\kappa \mathrm{B}$ activity in diabetic heart. In this context, only Feng et al have previously reported that miR-146a expression level decreases in the hearts of

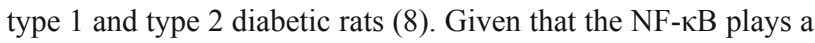
key role in the pathogenesis of diabetic heart complications, this study was conducted to explore whether microRNA-146a (as an NF-KB regulating factor) and its adapter proteins (TRAF6 and IRAK1) are affected by the diabetes in the rat heart. To evaluate this hypothesis, we measured the gene expression level of miR-

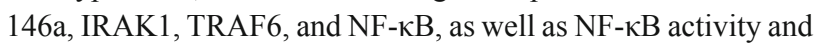
IRAK1 and TRAF6 protein levels in the heart of diabetic rats. Moreover, NF- $\kappa$ B activity was measured in response to miR-146a mimic transfection in human umbilical vein endothelial cells (HUVECs) under hyperglycemic condition.

\section{Materials and methods}

\section{Animal experiment}

Twelve male Sprague-Dawley rats (3 months old with $314 \pm$ $7 \mathrm{~g}$ of body weight; Razi Institute, Tehran, Iran) were housed in standard cages ( 3 rats in each), at room temperature $\left(22-25^{\circ} \mathrm{C}\right)$ with 12:12-h light/dark cycles and free access to food and water. The rats were randomized into control and diabetic groups $(n=6)$. This study was designed in accordance with US National Institutes of Health (NIH publication, No. 86-23, revised 1996) and ARRIVE guidelines for the care and use of animals approved by the Ethics Committee for the Use of Animals in Research at Hormozgan University of Medical Sciences (No: 93/3-1/6/13 Mar 2014) (20). Type 2 diabetes was induced by a single dose intraperitoneal injection of streptozotocin $(50 \mathrm{mg} / \mathrm{kg})$ dissolved in $0.1 \mathrm{M}$ of citrate buffer ( $\mathrm{pH} 4.5), 15 \mathrm{~min}$ after the intraperitoneal injection of nicotinamide (110 mg/kg; i.p.) in $12 \mathrm{~h}$ fasted rats (13). Citrate buffer was injected to control rats. Diabetes was defined as fasting blood glucose was higher than $250 \mathrm{mg} / \mathrm{dl}$ on 2 consecutive days, using glucometer (Arkray, Kyoto, Japan) (13). One day before sacrifice of rats, an oral glucose tolerance test (OGTT) was performed as previously described (13). The animals were killed 2 months after diabetes induction and the hearts were collected and stored at $-70{ }^{\circ} \mathrm{C}$. All manipulations were held in the morning.

\section{Cell culture and transfection of $m i R-146 a$}

HUVECs were purchased from the National Cell Bank of Iran (NCBI, Pasteur Institute, Tehran) and cultured in endothelial cell growth medium, EGM-2 Bullet kit (Lonza, Basel, Switzerland), according to the manufacturer's recommendations. Twenty four hours before transfection, the cells were passaged in 6-well plates, at the density of $3 \times 10^{5}$ cells/well in $2.3 \times 10^{3} \mu 1$ medium and incubated at standard culture condition for $24 \mathrm{~h}$. On the day of transfection, cell culture medium was replaced, and D-Glucose was added to the medium of control and hyperglycemic groups ( $5 \mathrm{mM}$ and 25 $\mathrm{mM}$, respectively) (8). D-Mannitol was used as osmotic control. Concurrently with the creation of cellular hyperglycemia, the HUVECs were transfected in parallel with hsa-miR-146a mimic or scramble (20 nmol/L) (Qiagen, Crawley, UK) using HiPerFect reagent (Qiagen), according to the manufacturer's protocol. All experiments were carried out for $24 \mathrm{~h}(8,22)$. Transfection efficiency was determined by real-time RT-PCR. Importantly, all data analyses were blinded.

\section{Real time RT-PCR analysis}

Twenty four hours after transfection, total RNA was isolated from HUVECs and left ventricular tissue using miRNeasy Mini Kit (Qiagen) according to the manufacturer's protocol. RNA quantity and quality were determined using Nanodrop (Thermo scientific) and agarose gel electrophoresis (Bio-Rad), respectively. Total RNA $(1 \mu \mathrm{g})$ was used for cDNA synthesis using miScript II RT cDNA synthesis Kit (Qiagen) according to the manufacturer's instructions. Each cDNA was used as a template for separate assay for miR-146a and mRNAs (IRAK, TRAF6 and NF- $\kappa B$ ) quantitative real-time RT-PCR by using miScript SYBR Green PCR Kit (Qiagen). All reactions were performed in duplicate on a Corbett RotorGene RG-6000 (Australia). The amount of PCR was normalized to that for housekeeping gene $\beta$ actin for mRNA samples, and U6 for miR-146a (Qiagen). The $2^{-\Delta \Delta \mathrm{Ct}}$ method was used for relative quantification of individual mRNAs and miR146a expression. The results have been expressed as fold change differences compared to the relevant controls.

\section{ELISA measurements}

ELISA kits were used for determination of cytoplasmic protein levels of TRAF6 (MyBioSource, San Diego, CA), IRAK1 (MyBioSource), and phosphorylated NF- $\kappa \mathrm{B}$ p65 as an index of NF- $\kappa B$ activity (Cayman chemicals, Ann Arbor, MI), as well as plasma insulin level (MyBioSource). Protein determination kit (Cayman chemicals) was used for detection of cytoplasmic protein concentration.

\section{Statistical analysis}

Data are expressed as mean $\pm \mathrm{SD}$, and were analyzed by repeated measures ANOVA (for analysis of the oral glucose tolerance test), one-way ANOVA (for analysis of data obtained from HUVECs) and independent $t$ test (for other parameters), using the SPSS 21.0 software (IBM, Armonk, NY, USA). The Tukey post hoc test was used to determine the differences between groups with significant $\mathrm{p}$-values. $\mathrm{p}<0.05$ was considered statistically significant.

\section{Results}

Blood glucose and insulin, body weight and OGTT

Fasting blood glucose and insulin levels in the diabetic rats were higher than those in the control counterparts at two months 

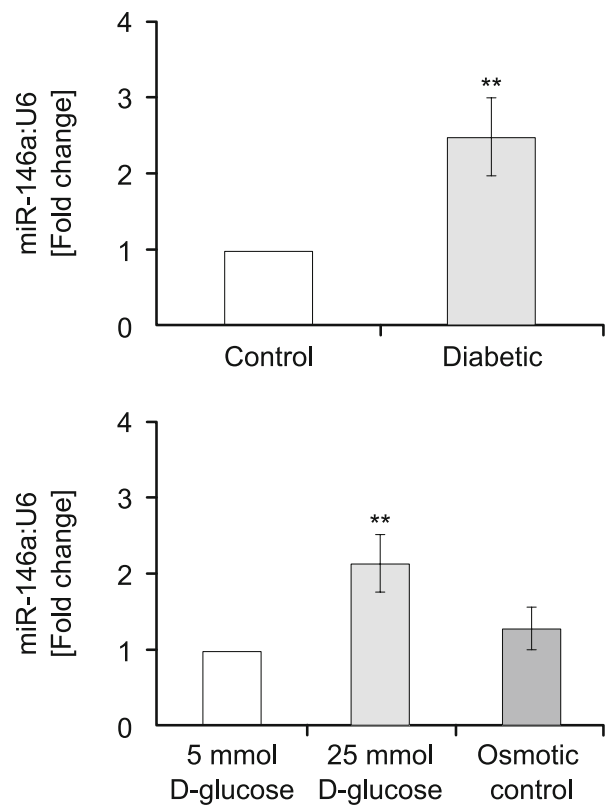

Fig. 1. Real-time quantitative RT-PCR analysis of miR-146a levels in animals' hearts, 2 months after induction of diabetes (a), and in human endothelial cells, HUVECs exposed to $5 \mathrm{mmol} / \mathrm{L}$ and $25 \mathrm{mmol} / \mathrm{L}$ D-glucose and osmotic control (5 mmol/L D-glucose $+20 \mathrm{mmol} / \mathrm{L} \mathrm{D}$ mannitol) (b). Bars represent Mean $\pm \mathrm{SD}, * * \mathbf{p}<0.01$ vs controls.

after diabetes induction $(349.63 \pm 13.44 \mathrm{vs} 97.88 \pm 11.23 \mathrm{mg} / \mathrm{dL}$, $\mathrm{p}=0.002$ for glucose, and $5.07 \pm 4.11 \mathrm{vs} 9.42 \pm 3.63 \mathrm{ng} / \mathrm{ml}, \mathrm{p}=$ 0.023 for insulin). Moreover, the diabetic rats showed a reduced body weight than the control rats $(253.29 \pm 14.02$ vs $415.40 \pm$ $28.74 \mathrm{~g}, \mathrm{p}=0.003$ ).

To confirm NIDDM, $24 \mathrm{~h}$ before sacrifice, the rats were enrolled for an OGTT. Before glucose intake (time 0), fasting blood glucose was higher in the diabetic group than in the control counterpart $(301.23 \pm 9.76 \mathrm{vs} 101.91 \pm 7.77 \mathrm{mg} / \mathrm{dL} ; \mathrm{p}=0.002)$. Sixty minutes after glucose intake $(2 \mathrm{~g} / \mathrm{kg})$, the blood glucose concentration in both diabetic and control groups reached maximum levels $(493.18 \pm 23.09$ and $288.10 \pm 12.66 \mathrm{mg} / \mathrm{dL}$, respectively), and then decreased to minimum levels at 120 minutes (401.22 \pm 9.84 vs $109.73 \pm 9.51 ; \mathrm{p}<0.001)$ however, it did not return to the baseline level in diabetic rats.

\section{miR-146a expression}

Real-time PCR analysis demonstrated that 2 months of uncontrolled diabetes causes a significant upregulation of miR-146a in diabetic rats hearts (Fig. 1a) $(p=0.003)$. Also, analysis of HUVECs in $25 \mathrm{mM}$ glucose confirmed significant upregulation of miR-146a compared with $5 \mathrm{mM}$ glucose $(\mathrm{p}=0.009)$. No significant effect was seen after incubation with $25 \mathrm{mM}$ D-Mannitol (Fig. 1b).

\section{$N F-\kappa B$ activity and TRAF6 and IRAK1 protein levels}

Figure $2 \mathrm{a}$ indicates that the NF- $\kappa \mathrm{B}$ activity was significantly increased in the heart of diabetic animals when compared with the non-diabetic rats $(p=0.023)$. Furthermore, 24 h hyperglycemia re-
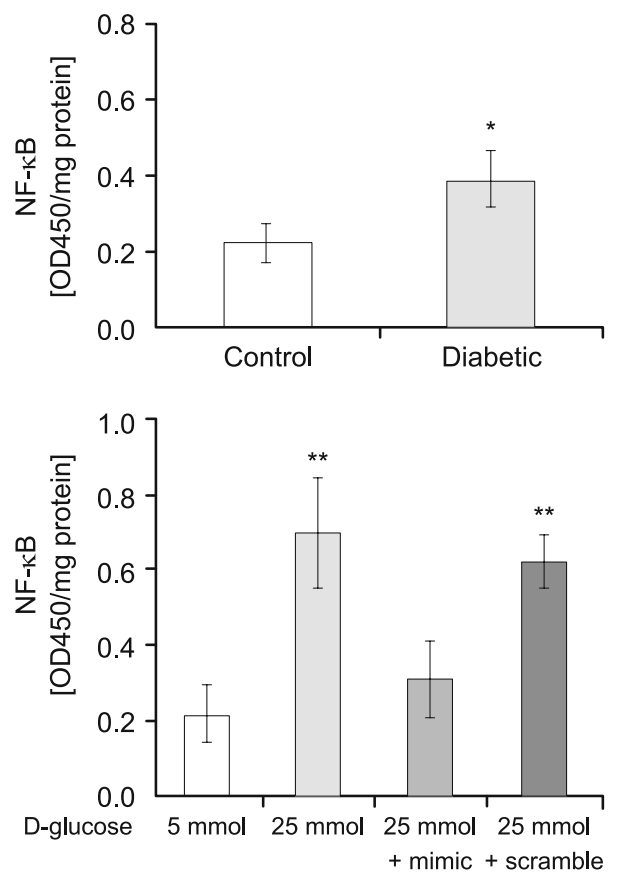

(c)

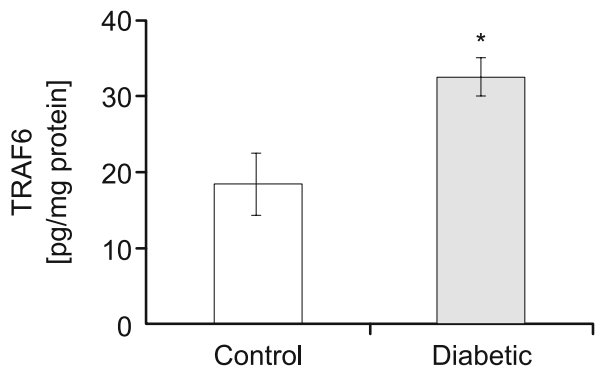

(d)

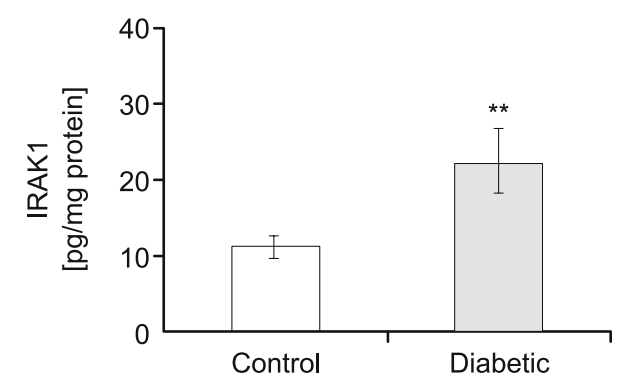

Fig. 2. ELISA measurements of NF-кB activity (a), TRAF6 (c) and IRAK1 (d) in the hearts of diabetic and control rats. Section (b) represents ELISA measurements of NF- $\mathrm{B}$ activity in HUVECs during normal (5 mmol/L D-glucose) and hyperglycemic (25 mmol/L D-glucose) condition, in the presence of miR-146a mimic or scramble. Bars represent mean $\pm \mathrm{SD} ;{ }^{*} \mathrm{p}<\mathbf{0 . 0 5}$, and $* * \mathrm{p}<0.01$ vs controls.

sults in a 3 fold increase in NF- $\kappa$ B activity in HUVECs (Fig. 2b) (p $=0.007$ ). Transfection of miR-146a mimic prevented from a significant increase of NF- $\kappa$ B activity in HUVECs (Fig. 2b). Moreover, no significant effect was seen by transfection of scramble microRNA.

ELISA measurements demonstrated that TRAF6 and IRAK1 protein levels were significantly higher in the diabetic hearts than 


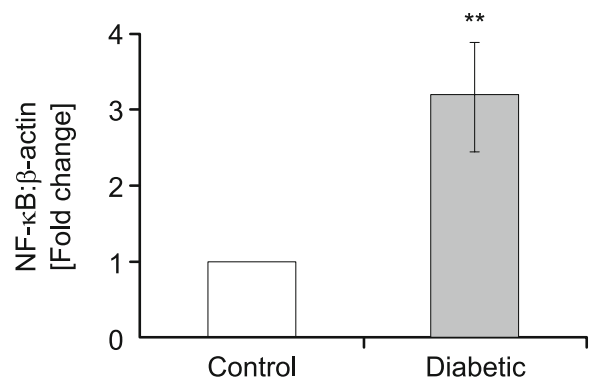

(b)

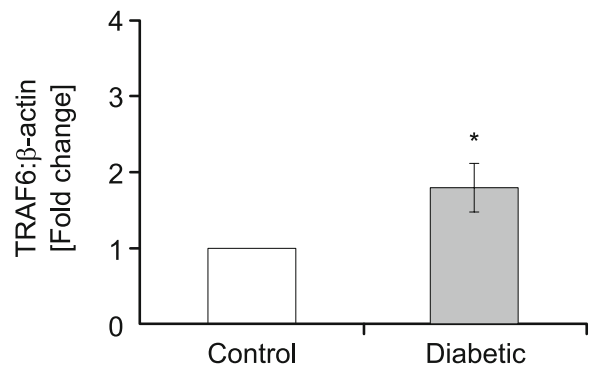

c

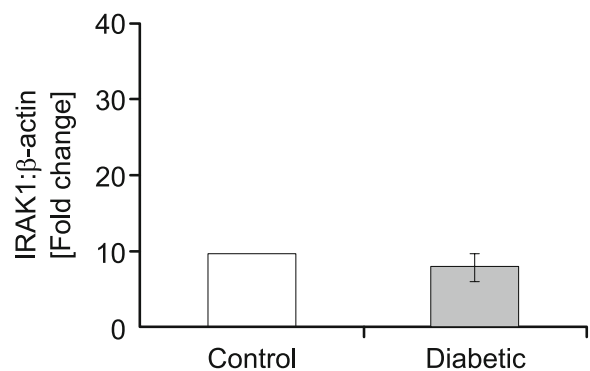

Fig. 3. The mRNA expression levels of NF-kB (a), TRAF6 (b) and IRAK1 (c) in the heart of diabetic and control rats. Data are presented as mean $\pm \mathrm{SD} ; * \mathbf{p}<0.05$, and ** $\mathrm{p}<0.01$ vs controls

in the control group (Fig. $2 \mathrm{c}$ and $2 \mathrm{~d})(\mathrm{p}=0.012$ and $\mathrm{p}=0.009$, respectively).

\section{The $m R N A$ expression level of TRAF6, IRAKI and $N F-\kappa B$}

Figure 3 represents the changes of cardiac TRAF6, IRAK1 and NF- $\mathrm{B}$ mRNA expression level 2 months after diabetes induction. In comparison to the normal control rats, 2 months uncontrolled diabetes enhanced TRAF6 and NF- $\mathrm{kB}$ mRNA expression levels in the heart of diabetic rats ( $p=0.007$ and $p=0.01$, respectively), while it had no significant effect on IRAK1 gene expression level $(\mathrm{p}=0.09)$.

\section{Discussion}

The main finding of this study was a significant upregulation of miR-146a in diabetic heart, 2 months after uncontrolled diabetes. Also, remarkable upregulation of NF-kB and TRAF6 mRNA levels, and increases in NF-kB p65 subunit, TRAF6 and IRAK1 protein concentrations were seen in the diabetic hearts. Moreover, it was observed that transfection of miR-146a mimic prevented from a significant increase of NF- $\mathrm{KB}$ activity in HUVECs during hyperglycemic condition.

In the present study, nicotinamide-STZ model was used for relative destruction of pancreatic $\beta$ cells. This model of experimental diabetes is economical, and remains stable for a long period with a low mortality rate $(23,24)$. Furthermore, this model induces type 2 diabetes easily and in a short period of time, and it closely resembles the diabetic pattern seen in non-obese diabetic patients (24). The results obtained by OGTT and fasting blood insulin in this study are in line with previous performed works $(21,25)$, and confirm the induction of type 2 diabetes.

It has been widely accepted that sustained hyperglycemia enhances some intracellular factors including protein kinase $\mathrm{C}$, reactive oxygen spices, polyols, and also activates hexosamines and advanced glycation end products pathways converging to activate a master switch pro-inflammatory transcription factor, NF-кB (26). This factor, in turn activates several pro-inflammatory cytokine genes, and thereby promotes the cells toward inflammation and finally apoptosis (26). Increased NF-KB activity in hyperglycemic HUVECs and in the heart of our diabetic rats is in agreement with earlier observations, and confirms hyperglycemia-induced inflammation (26).

It has been proposed that $\mathrm{NF}-\mathrm{\kappa B}$ regulates its own activation in part through separate negative feedback loops by transactivation of several microRNAs such as miR-155, miR-34, miR-21, and miR-146a (27). It is believed that NF-KB activation upregulates miR-146a gene that, upon processing and maturation, enters to cytoplasm and prevents from translation of IRAK1 and TRAF6 mRNAs to proteins $(17,27)$. These two adapter molecules activate inhibitory kinase B kinases (Ikks) which in turn, phosphorylate inhibitory kinase B (IkB) to release NF-кB from its inhibition (17). Indeed, it has been suggested that miR-146a negatively regulates the NF-КB activation by reduction of IRAK 1 and TRAF6 proteins (17). However, this negative feedback loop has not been demonstrated by some investigations $(12,13,18,19)$.

Overexpression of miR-146a in hyperglycemic HUVECs and in the heart of our diabetic rats presumably resulted from the NF$к B$ activation for negative feedback purpose. Surprisingly, this overexpression of miR-146a was not accompanied by downregulation of IRAK1 and TRAF6 mRNAs and proteins. One explanation for this observed result may be the possibility that IRAK1 and TRAF6 to be under other levels of control, such as Toll-like receptor activators like pro-inflammatory cytokines $(19,22)$. Increased miR-146a expression has also been documented in diabetic kidney (13), and in plasma and limbal corneal epithelium compartment of diabetic patients $(14,15)$. On the other hand, decreased expression of miR-146a has been reported in diabetic mouse wounds (5), diabetic kidney and dorsal root ganglia $(8,9)$, glycated albumin- and high glucose-stimulated endothelial cells (10), and in serum and peripheral blood mononuclear cells of type 1 and 2 diabetic patients $(11,12)$. Furthermore, we previously reported the down-regulation of miR-146a in diabetic rats' aorta and sciatic nerve $(6,7)$. To the best of our knowledge, only Feng et al have previously reported that miR-146a expression level decreases in the hearts of type 1 and type 2 diabetic rats (8). This 


\section{6-170}

is the first presentation of data on up-regulation of miR-146a in diabetic heart with significant up-regulation of IRAK1 and TRAF6 mRNAs and proteins. At present, the cause of different behavior of miR-146a in different tissues is unclear. But it may depend on tissue type, blood and tissue cytokines concentrations, timing, and duration of inflammation.

This study demonstrated that while miR-146a and NF-кB are up-regulated in HUVECs under hyperglycemic condition, transfection of miR-146a mimic prevents from enhancement of $\mathrm{NF}-\mathrm{KB}$ activity. This result supports the anti-inflammatory role of miR-146a in the pathogenesis of diabetes related complications.

Overall, given the activation of NF- $\mathrm{BB}$ to be a key step in the progression of diabetic complications $(26,28)$, the results of present study may suggest that presumably a defect in the regulation of IRAK 1 and TRAF6 can weaken miR-146a regulatory negative feedback loop and provides a situation for sustained activation of NF- $\mathrm{kB}$ and its targets to promote cells toward abnormalities; however, this suggestion needs to be confirmed by measurement of IKKs activity or concentration.

\section{References}

1. Kalninova J, Jakus V, Glejtkova M, Kuracka L, Sandorova E. Impact of glycemic control on advanced glycation and inflammation in overweight and obese patients with type 2 diabetes mellitus. Bratisl Lek Listy 2014; 115 (8): 457-468.

2. Martín-Timón I, Sevillano-Collantes C, Segura-Galindo A, Del Cañizo-Gómez FJ. Type 2 diabetes and cardiovascular disease: Have all risk factors the same strength? World J Diabetes 2014; 5 (4): 444-470.

3. Kawahito S, Kitahata H, Oshita S. Problems associated with glucose toxicity: Role of hyperglycemia-induced oxidative stress. World J Gastroenterol 2009; 15 (33): 4137-4142.

4. Arslan M, Comu FM, Kip G, Alkan M, Kiraz HA, Ozer A, Sivgin V. Effect of dexmedetomidine on erythrocyte deformability during ischaemia-reperfusion injury of heart in diabetic rats. Bratisl Lek Listy 2014; 115 (8): 494-497.

5. Xu J, Wu W, Zhang L et al. The role of microRNA-146a in the pathogenesis of the diabetic wound-healing impairment: correction with mesenchymal stem cell treatment. Diabetes 2012; 61 (11): 2906-2912.

6. Emadi SS, Soufi FG, Khamaneh AM, Alipour MR. MicroRNA-146a expression and its intervention in NF-KB signaling pathway in diabetic rat aorta. Endocr Regul 2014; 48 (2): 103-108.

7. Yousefzadeh N, Alipour MR, Soufi FG. Deregulation of NF-кB-miR146a negative feedback loop may be involved in the pathogenesis of diabetic neuropathy. J Physiol Biochem 2015; 71 (1): 51-58.

8. Feng B, Chen S, McArthur K et al. miR-146a-Mediated extracellular matrix protein production in chronic diabetes complications. Diabetes 2011; 60 (11): 2975-2984.

9. Wang L, Chopp M, Szalad A et al. The role of miR-146a in dorsal root ganglia neurons of experimental diabetic peripheral neuropathy. Neuroscience 2014 ; 259: 155-163.

10. Wang HJ, Huang YL, Shih YY, Wu HY, Peng CT, Lo WY. MicroRNA- 146a decreases high glucose/thrombin-induced endothelial inflammation by inhibiting NAPDH oxidase 4 expression. Mediators Inflamm 2014; 2014: 379537.
11. Baldeón R L, Weigelt $\mathbf{K}$, de Wit $\mathbf{H}$ et al. Decreased serum level of miR-146a as sign of chronic inflammation in type 2 diabetic patients. PLoS One 2014; 9 (12): e115209.

12. Balasubramanyam M, Aravind S, Gokulakrishnan K et al. Impaired miR-146a expression links subclinical inflammation and insulin resistance in Type 2 diabetes. Mol Cell Biochem 2011; 351 (1-2): 197-205.

13. Alipour MR, Khamaneh AM, Yousefzadeh N, Mohammad-nejad D, Soufi FG. Upregulation of microRNA-146a was not accompanied by downregulation of pro-inflammatory markers in diabetic kidney. Mol Biol Rep 2013; 40 (11): 6477-6483.

14. Rong Y, Bao W, Shan $\mathbf{Z}$ et al. Increased microRNA-146a levels in plasma of patients with newly diagnosed type 2 diabetes mellitus. PLoS One 2013; 8 (9): e73272.

15. Winkler MA, Dib C, Ljubimov AV, Saghizadeh M. Targeting miR146a to treat delayed wound healing in human diabetic organ-cultured corneas. PLoS One 2014; 9 (12): e114692.

16. Cheng HS, Njock MS, Khyzha N, Dang LT, Fish JE. Noncoding RNAs regulate NF- $\mathrm{kB}$ signaling to modulate blood vessel inflammation. Front Genet 2014; 5: 422.

17. Saba R, Sorensen DL, Booth SA. MicroRNA-146a: A Dominant, Negative Regulator of the Innate Immune Response. Front Immunol 2014; 5: 578.

18. Liu Z, Xiao B, Tang B et al. Up-regulated microRNA-146a negatively modulate Helicobacter pylori-induced inflammatory response in human gastric epithelial cells. Microbes Infect 2010; 12 (11): 854-863.

19. Zilahi E, Tarr T, Papp G, Griger Z, Sipka S, Zeher M. Increased microRNA-146a/b, TRAF6 gene and decreased IRAK1 gene expressions in the peripheral mononuclear cells of patients with Sjögren's syndrome. Immunol Lett 2012; 141 (2): 165-168.

20. Kilkenny C, Browne WJ, Cuthill IC, Emerson M, Altman DG. Improving bioscience research reporting: the ARRIVE guidelines for reporting animal research. PLoS Biol 2010; 8 (6): e1000412.

21. Mohammadshahi M, Haidari F, Soufi FG. Chronic resveratrol administration improves diabetic cardiomyopathy in part by reducing oxidative stress. Cardiol J 2014; 21 (1): 39-46.

22. Rau CS, Yang JC, Chen YC et al. Lipopolysaccharide-induced microRNA-146a targets CARD10 and regulates angiogenesis in human umbilical vein endothelial cells. Toxicol Sci 2014; 140 (2): 315-326.

23. Szkudelski T. Streptozotocin-nicotinamide-induced diabetes in the rat. Characteristics of the experimental model. Exp Biol Med (Maywood) 2012; 237 (5): 481-490.

24. Islam MS, Wilson RD. Experimentally induced rodent models of type 2 diabetes. Methods Mol Biol 2012; 933: 161-174.

25. Palsamy P, Subramanian S. Resveratrol, a natural phytoalexin, normalizes hyperglycemia in streptozotocin-nicotinamide induced experimental diabetic rats. Biomed Pharmacother 2008; 62 (9): 598-605.

26. Fiorentino TV, Prioletta A, Zuo P, Folli F. Hyperglycemia-induced oxidative stress and its role in diabetes mellitus related cardiovascular diseases. Curr Pharm Des 2013; 19 (32): 5695-5703.

27. Ma X, Becker Buscaglia LE, Barker JR, Li Y. MicroRNAs in NFkappa B signaling. J Mol Cell Biol 2011; 3 (3): 159-166.

28. Patel S, Santani D. Role of NF-kappa B in the pathogenesis of diabetes and its associated complications. Pharmacol Rep 2009; 61 (4): 595-603.

Received June 5, 2015. Accepted November 11, 2015. 